УДК 331.461

БЕЗОПАСНОЕ ИСПОЛНЕНИЕ ТРУДОВЫХ ОБЯЗАННОСТЕЙ ФУНДАМЕНТ СИСТЕМЫ УПРАВЛЕНИЯ ПРОФЕССИОНАЛЬНЫМИ РИСКАМИ В ОРГАНИЗАЦИИ

SAFE EXECUTION OF LABOR RESPONSIBILITIES

IS THE BASIS OF THE PROFESSIONAL RISK MANAGEMENT

SYSTEM IN THE ENTERPRISE

\title{
P.P. Шангареев
}

Уфимский государственный нефтяной технический университет, филиал, г. Октябрьский, Российская Федерация

\section{Rustam R. Shangareyev}

Ufa State Petroleum Technological University, branch, Oktyabrskiy, Russian Federation

$$
\text { e-mail: shagu64@mail.ru }
$$

Аннотация. В статье обоснована актуальность проблемы снижения показателей производственного травматизма и профессиональной заболеваемости. Показано, что в настоящее время в России осуществляется переход от компенсационной модели, основанной на выплатах за вредные и опасные условия труда, к системе управления и минимизации профессиональных рисков, которая должна оперативно реализовывать превентивные подходы к сохранению здоровья работников и сократить издержки, связанные с воздействием негативных факторов производственной среды.

Указывается, что для решения задач по данным вопросам необходимо научить и мотивировать работника предвидеть опасные ситуации или 
условия труда, анализировать профессиональные риски и своевременно их предотвращать.

Результаты расследований большинства несчастных случаев говорят о том, что их главная причина - неумение работников заблаговременно выявлять и устранять источники опасностей, образующих профессиональные риски. Отказы оборудования, отклонения в технологических процессах могут привести к трагичным последствиям, связанным с человеческими жизнями и значительными финансовыми потерями предприятия, поэтому автором рекомендуются применение упреждающего подхода к выявлению и учету профессиональных рисков и использование передового комплекса методов и инструментов управления всеми видами процессов, оказывающих влияние на безопасность предприятия и позволяющих предотвращать реализацию негативных событий.

В качестве примера опасного поведения работников и управленческих ошибок при решении организационных вопросов по охране труда автор статьи, работавший в Государственной инспекции по охране труда в Республике Башкортостан, приводит результаты дополнительного расследования группового несчастного случая, происшедшего в 2011 г. на Яновской площади Знаменского месторождения, и причины техногенной аварии. Отмечено, что в обозримом будущем вряд ли удастся создать полностью травмобезопасную производственную среду, следовательно, ключевым моментом, определяющим уровень профессиональных рисков в системе управления профессиональными рисками, станет «человеческий фактор».

Сделан вывод о том, что проведение работ по идентификации и оценке профессиональных рисков при выполнении основных технологических операций в нефтегазовом комплексе и разработка доступной для понимания работниками методологии управления профессиональными рисками обосновывают необходимость выполнения дальнейших научных 
исследований в данной области и решения актуальных научнопрактических задач, которые ставят перед собой специалисты, причём как в России, так и в странах ЕC.

Abstract. The article presents the relevance of the problem associated with a decrease in occupational injuries and occupational morbidity. It is shown that at present Russia is undergoing a transition from a compensation model based on payments for harmful and dangerous working conditions to a system of management and minimization of professional risks, which should quickly implement preventive approaches to preserve the health of workers and reduce costs associated with the impact of negative environmental factors.

It is indicated that to solve problems on these issues, it is necessary to teach and motivate the employee to anticipate dangerous situations or working conditions, analyze professional risks and prevent them in a timely manner. The results of investigations of most accidents indicate that their main reason is the inability of workers to identify and eliminate sources of hazards that create occupational hazards in advance. Failures of equipment, deviations in technological processes can lead to tragic consequences associated with human lives and significant financial losses of the enterprise. Therefore, the author recommends the use of a proactive approach to identifying and accounting for professional risks, using an advanced set of methods, approaches and tools for managing all kinds of processes that affect the safety of the enterprise, which will prevent the implementation of negative events.

As an example of the dangerous behavior of workers and managerial errors in solving organizational issues of labor protection, the author of the article, who worked at the State Inspectorate for Labor Protection in the Republic of Bashkortostan, cites the results of an additional investigation of a group accident that occurred in 2011 on Yanovskaya Square of the Znamensky oil field and the man-caused accident causes. It is noted that in the foreseeable future unlikely it will be possible to create a completely safety-free working environment, 
therefore, the «human factor» will become the key moment determining the professional risks level in the professional risk management system.

It is concluded that the work on identification and assessment of professional risks in the basic technological operations performance in the oil and gas complex, and the development of a methodology for managing professional risks accessible for employees to understand, justifies the need to carry out further scientific research in this area and solve urgent scientific and practical problems that pose experts are in front of us, both in Russia and in the EU countries.

Ключевые слова: охрана труда; работник; работодатель; опасность; профессиональный риск; травматизм; расследование; скважина; система; управление; безопасность

Key words: labor protection; employee; employer; danger; professional risk; injuries; investigation; well; system; management; safety

Снижение показателей производственного травматизма как следствия несчастных случаев и аварий давно является одной из актуальных проблем во всем мире [1].

Отечественная экономика ежегодно теряет 1,5 трлн руб. из-за потерь, вызванных профессиональными заболеваниями, травмами и компенсациями, что требует проведения модернизации системы охраны труда, поиска новых подходов и эффективных решений [2].

Статистика показывает, что динамика изменения показателей аварийности и несчастных случаев со смертельным исходом на опасных производственных объектах нефтегазового комплекса имеет цикличный характер и остается высокой (рисунок 1) [3]. 


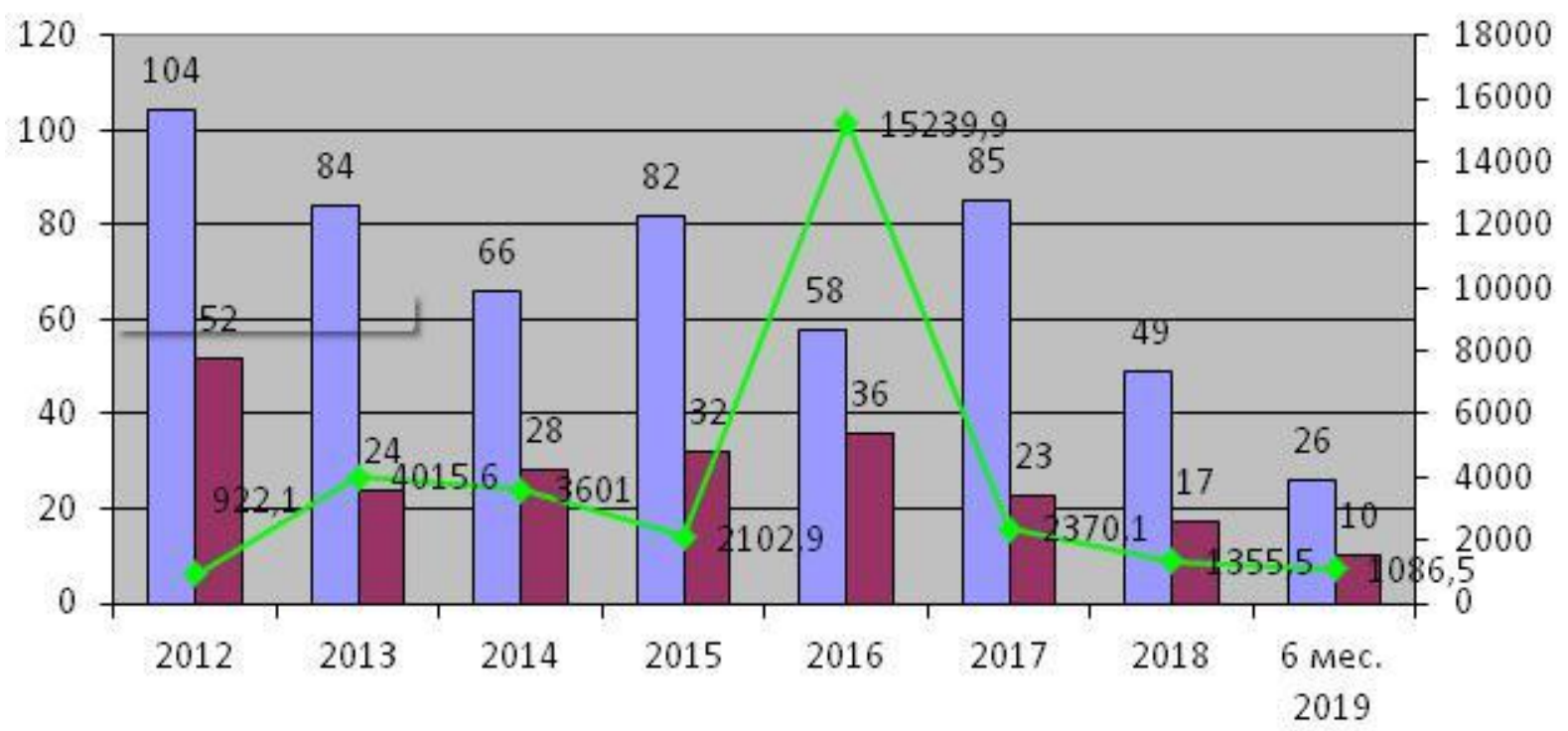

Аварии $\square$ смертельныеслучаи $\nleftarrow$ Ущерб,млн. руб.

Рисунок 1. Динамика аварийности и производственного травматизма со смертельным исходом на опасных производственных объектах нефтегазового комплекса

В настоящее время в России осуществляется переход от компенсационной модели, основанной на выплатах за вредные и опасные условия труда, к системе оценки, управления и минимизации профессиональных рисков, которая должна оперативно реализовывать превентивные подходы к сохранению здоровья работников и сократить издержки, связанные с воздействием негативных факторов производственной среды.

Практика развитых стран показывает, что технологическая модернизация экономики не способна в одиночку эффективно обеспечивать безопасность на производстве, если в системе «человек машина» человеческий фактор $\mathrm{c}$ точки зрения прогнозирования взаимодействия остается непредсказуемым звеном. Наиболее типичной причиной умышленных нарушений требований охраны труда является стремление человека за счет этого сделать работу легче, быстрее и проще. В таких случаях при относительно низком уровне заработной платы в России (таблица 1) для эффективного применения механизма мотивации 
необходимо, чтобы расходы от нарушений правил безопасности работниками превышали полученные за счет этого выгоды [4]. При этом целесообразнее использовать не отрицательное (наказание), а положительное и индивидуальное (на основе механизма мотивации системы управления профессиональными рисками) стимулирование за безопасную работу [5]. Безопасное поведение работника должно быть осознанным, а его знания, навыки и умения, определяющие компетентность, являться фундаментом системы охраны труда в организации [6].

Таблица 1. Средняя заработная плата в России и других странах мира в 2019 г.

\begin{tabular}{|l|c|}
\hline \multicolumn{1}{|c|}{ Страны мира } & $\begin{array}{c}\text { Среднемесячная зарплата, } \\
\text { долл. США }\end{array}$ \\
\hline Швейцария & 6400 \\
\hline Норвегия & 4800 \\
\hline США & 4500 \\
\hline Германия & 4300 \\
\hline Япония & 4100 \\
\hline Южная Корея & 2800 \\
\hline Польша & 1480 \\
\hline Греция & 1290 \\
\hline Эстония & 1270 \\
\hline Чили & 1220 \\
\hline Словакия & 1050 \\
\hline Китай & 840 \\
\hline Турция & 820 \\
\hline Румыния & 690 \\
\hline Россия & 670 \\
\hline
\end{tabular}

Общая проблема стандартных систем управления профессиональными рисками (СУПР) - сложность методологии и оторванность от реальности, отсутствие понятных и действенных методов, которые вовлекают каждого сотрудника в процесс. Работники лучше многих руководителей знают о 
возможных опасностях на рабочих местах и о том, что может привести к сбою при выполнении той или иной технологической операции. Чтобы решать задачи, связанные с данными вопросами, необходимо научить и, главное, мотивировать работника предвидеть опасные ситуации или условия труда, анализировать профессиональные риски и своевременно их предотвращать. Поэтому особая роль в становлении осознанной культуры безопасности для мотивированного перехода от отношения к охране труда - «нам приказали - мы делаем для выполнения задания в срок» - к отношению - «мы делаем это потому, что это нужно нам для сохранения жизни, здоровья и получения достойной заработной платы» - отводится каждому работнику.

Результаты расследований большинства несчастных случаев говорят о том, что их главная причина - неумение работников заблаговременно выявлять и устранять источники опасностей, образующих профессиональные риски. Технологическая безопасность - это способ управления объектами на протяжении всего срока их эксплуатации с целью недопущения непреднамеренного выхода из процесса опасных материалов или энергии, что крайне важно в условиях негативных факторов производственной среды нефтегазового комплекса. Управление технологической безопасностью является частью СУПР в организации. Отказы оборудования, отклонения в технологических процессах могут привести к трагичным последствиям, связанным с человеческими жизнями и значительными финансовыми потерями предприятия. При таких условиях необходимо применение упреждающего подхода к выявлению и учету профессиональных рисков с использованием передового комплекса методов, подходов и инструментов управления всеми видами процессов, оказывающих влияние на безопасность предприятия, которые позволят предотвращать реализацию негативных событий (включая этапы проектирования, применения соответствующих технических и эксплуатационных стандартов и «барьеров»). 
В нефтедобыче факторы комплексного характера вызывают пожаро- и взрывоопасность производственной среды. Известно, что в процессе выполнения работ на скважинах персонал постоянно находится среди легковоспламеняющихся веществ, на одежде работающих накапливается статическое электричество, разряд которого может привести к воспламенению нефти (нефтепродуктов) или взрыву газа, пожару и непоправимым последствиям с человеческими жертвами [7]. В 2011 г. автор статьи, работавший в Государственной инспекции труда (по охране труда) в Республике Башкортостан до проведения процессов оптимизации в органах федеральной госслужбы, провел дополнительное расследование группового несчастного случая, произошедшего на Яновской площади Знаменского месторождения [8].

При проведении текущего ремонта скважины № 1292 НГДУ «Ишимбай-Нефть» ООО «Башнефть-Добыча» было установлено, что произошёл обрыв насосно-компрессорных труб (НКТ), что привело к их падению на забой. В соответствии с планом работы по извлечению оборвавшихся при эксплуатации НКТ с глубинно-насосным оборудованием производились бригадой по капитальному ремонту скважин (КРС) Приютовского цеха Уфимского управления подземного и капитального ремонта скважин. После завершения ловильных работ была выполнена смена объема жидкости в скважине.

11 июня 2011 г. при подъеме труб произошел излив небольшого объема нефти из скважины через трубный канал НКТ. После герметизации устья скважины давление в трубном пространстве на устье скважины составило около 8 атм. Подъем НКТ был продолжен без постоянного долива скважины и поддержания уровня жидкости на устье. Далее в соответствии с планом работ необходимо было произвести дополнительную перфорацию в существующем интервале скважины. Для этого требовалось спустить в неё НКТ со скошенным концом и шаблоном с последующей промывкой забоя. Для промывки скважины методом круговой циркуляции 
через желобную систему была использована задавочная жидкость в объеме $8 \mathrm{~m}^{3}$ с плотностью 1,03 г/ $\mathrm{cm}^{3}$. Был выполнен спуск НКТ с пакером и проведена опрессовка эксплуатационной колонны.

14 июня 2011 г. после промывки забоя скважины на время проведения перфорации устье было оборудовано превентором. Кумулятивную перфорацию согласно техническому регламенту на прострелочные и взрывные работы провела партия Октябрьского управления геофизических работ. Не имея оперативной информации от геофизиков о повышении уровня жидкости после проведенной перфорации в скважине, бригада КРС демонтировала превентор, установила колонный фланец и продолжила спуск НКТ с пакером с целью проведения соляно-кислотной обработки призабойной зоны скважины. Вечером начался выброс газированного флюида, не позволивший рабочим оперативно герметизировать устье. В результате неконтролируемого фонтанирования и выброса из скважины газонефтяной смеси в зоне работы механизмов подъёмного агрегата возникла взрывоопасная концентрация веществ в воздухе рабочей зоны. Произошел взрыв газовоздушной смеси с последующим возгоранием газа и пожаром, который удалось ликвидировать только силами прибывшего на место аварии пожарного расчета. Оперативная группа Башкирского отряда противофонтанной военизированной части произвела герметизацию устья и глушение скважины. Бурильщик и машинист агрегата бригады КРС получили тяжёлые термические ожоги тела и дыхательных путей. От полученных повреждений здоровья машинист подъемника впоследствии скончался.

В ходе расследования было установлено, что основной причиной чрезвычайного происшествия, приведшего к человеческим жертвам, стало нарушение технологического процесса при производстве работ. Не была проведена операция глушения скважины для обеспечения превышения гидростатического давления столба жидкости над пластовым давлением. В результате спуско-подъемные операции и прострелочно-взрывные работы на скважине выполнялись с нарушениями плана производства работ, в 
условиях депрессии и без заполнения ствола скважины для поддержания необходимого уровня жидкости на устье. Сопутствующей причиной явилась неудовлетворительная организация производства работ, выраженная в отсутствии ряда требуемых по нормам безопасности технологических операций в плане работ (например, установки на устье противовыбросового оборудования при условиях, когда не исключалась возможность самопроизвольного поступления пластового флюида, указания неверного значения пластового давления и т.д.).

Техногенной аварии с человеческими жертвами можно было избежать при условии соблюдения норм Трудового кодекса РФ, Федерального закона «О промышленной безопасности опасных производственных объектов» и «Правил безопасности в нефтяной и газовой промышленности», которые обязывают ответственных лиц обеспечить безопасность технологических процессов, информирование персонала о профессиональных рисках и принятие мер по предотвращению аварийных ситуаций и сохранению жизни и здоровья работников [9-11].

Умение идентифицировать опасности на любой стадии технологического процесса производства, определять их характеристики, устанавливать интенсивность и продолжительность воздействия, причину возникновения и возможный результат негативного воздействия, что позволит свести к минимальному уровню риски происшествий, имеет сегодня большое значение для обеспечения охраны труда персонала.

При формировании СУПР необходимо учитывать два важнейших вывода аксиомы о потенциальной опасности деятельности:

1) невозможно разработать (найти) абсолютно безопасный вид деятельности человека, разработать абсолютно безопасную технику;

2) ни один вид деятельности не может обеспечить абсолютную безопасность для человека (нулевой риск).

В обозримом будущем вряд ли удастся создать полностью травмобезопасную производственную среду, следовательно, ключевым 
моментом, определяющим уровень профессиональных рисков в СУПР, станет «человеческий фактор», выражаемый в форме опасного поведения работника и управленческих ошибок при решении организационных вопросов по охране труда [12].

Управление профессиональными рисками может стать эффективным в системе охраны труда, если работники, прошедшие соответствующее обучение, будут принимать в процессе непосредственное участие, для чего необходим эффективный механизм их мотивации и постоянного повышения уровня компетентности в этой области [13]. Такая система может стать реальным инструментом, при помощи которого возможно постоянное выявление источников возникновения опасностей на рабочих местах для целевого расходования средств на снижение уровня их негативного воздействия либо ликвидацию, что позволит сократить количество травм, обусловленных опасными действиями персонала, и значительно снизить уровни профессиональных рисков предприятий. В конечном итоге, человеческий фактор должен стать надежным звеном в системе мероприятий обеспечения безопасного труда.

Проведение работ по идентификации и оценке профессиональных рисков при выполнении основных технологических операций в нефтегазовом комплексе и разработка доступной для понимания работниками методологии управления профессиональными рисками обосновывает необходимость выполнения дальнейших научных исследований в данной области и решения актуальных научнопрактических задач, которые ставят перед собой специалисты, причём как в России, так и в странах ЕС [14].

\section{Выводы}

Показано, что в настоящее время в России осуществляется переход от компенсационной модели, основанной на выплатах за вредные и опасные условия труда, к системе управления и минимизации профессиональных 
рисков, которая должна оперативно реализовывать превентивные подходы к сохранению здоровья работников и сократить издержки, связанные с воздействием негативных факторов производственной среды. Указывается, что для решения задач по данным вопросам необходимо научить и мотивировать работника предвидеть опасные ситуации или условия труда, анализировать профессиональные риски и своевременно их предотвращать.

Результаты расследований большинства несчастных случаев говорят о том, что их главная причина - неумение работников заблаговременно выявлять и устранять источники опасностей, образующих профессиональные риски. Отказы оборудования, отклонения в технологических процессах могут привести к трагичным последствиям, связанным с человеческими жизнями и значительными финансовыми потерями предприятия, поэтому автором рекомендуются применение упреждающего подхода к выявлению и учету профессиональных рисков и использование передового комплекса методов и инструментов управления всеми видами процессов, оказывающих влияние на безопасность предприятия и позволяющих предотвращать реализацию негативных событий.

Отмечено, что в обозримом будущем вряд ли удастся создать полностью травмобезопасную производственную среду, следовательно, ключевым моментом, определяющим уровень профессиональных рисков в системе управления профессиональными рисками, станет «человеческий фактор».

Сделан вывод о том, что проведение работ по идентификации и оценке профессиональных рисков при выполнении основных технологических операций в нефтегазовом комплексе и разработка доступной для понимания работниками методологии управления профессиональными рисками обосновывают необходимость выполнения дальнейших научных исследований в данной области и решения актуальных научнопрактических задач, которые ставят перед собой специалисты, причём как в России, так и в странах ЕC. 


\section{Список используемых источников}

1. Абдрахимов Ю.Р., Шангареев Р.Р. Об актуальности вопросов изучения профессиональных рисков в России // Современные технологии в нефтегазовом деле - 2014: сб. тр. междунар. науч.-техн. конф.: В 2 Т. Уфа: Аркаим, 2014. Т. 2. С. 7-10.

2. Зубкова А., Сушкина А. Модернизация системы управления охраной труда // Кадровик. 2012. № 7. С. 62-66.

3. Приказ Ростехнадзора № 339 от 02.09.2019. Доклад о правоприменительной практике контрольно-надзорной деятельности в Федеральной службе по экологическому, технологическому и атомному надзору при осуществлении федерального государственного надзора в области промышленной безопасности за 6 месяцев 2019 года // Консорциум Кодекс. URL: http://docs2.cntd.ru/document/561135145 (дата обращения: 14.01.2020).

4. Средняя зарплата по регионам России и в других странах мира в 2019 году // Деловая жизнь. URL: http://bs-life.ru/rabota/3/srednyayazarplata2019.html (дата обращения: 16.01.2020).

5. Shangareev R.R. Role of Employee Motivation in an Industrial Occupational Risk Management System // IOP Conference Series Earth and Environmental Science. 2018. Vol. 194. № 2. P. 022033. DOI: 10.1088/17551315/194/2/022033.

6. Гусейнова Е.Л. Компетентность и компетенция // Современные технологии в нефтегазовом деле - 2016: сб. тр. междунар. науч.-техн. конф., посвященной 60-летию филиала: В 2 Т. Уфа: УГНТУ, 2016. Т. 2. С. 224-227.

7. Шангареев Р.Р., Сираев А.З. Идентификация и оценка профессиональных рисков при погрузочно-разгрузочных работах на объектах добычи нефти и газа // Матер. 46-й Всеросс. науч.-техн. конф. молодых ученых, аспирантов и студентов с международным участием: В 2 Т. Уфа: УГНТУ, 2019. Т. 2. С. 199-203. 
8. Обстоятельства и причины крупных аварий и несчастных случаев, происшедших на объектах нефтегазодобычи в 1-м полугодии 2011 г. // Информационный бюллетень Федеральной службы по экологическому, технологическому и атомному надзору. 2011. № 5 (56). C. 5-8. URL: https://ib.safety.ru/assets/pdf/Bull_56/Bull_56_5-8.pdf (дата обращения: 17.01.2020).

9. Трудовой кодекс Российской Федерации от 30.12.2001 № 197-Ф3 (с посл. изм. и доп. от 16.12.2019г.) // Официальный интернет-портал правовой информации. URL: http://pravo.gov.ru/proxy/ips/?docbody= \&nd=102074279 (дата обращения: 21.01.2020).

10. Федеральный закон от 21.07.1997 № 116-Ф3 «О промышленной безопасности опасных производственных объектов» (с посл. изм. и доп. от 29.07.2018). М.: Норматика, 2019. 28 с.

11. Приказ Ростехнадзора № 101 от 12.03.2013. Об утверждении Федеральных норм и правил в области промышленной безопасности «Правила безопасности в нефтяной и газовой промышленности» (с посл. изм. и доп. от 12.01.2015) // Информационно-правовое обеспечение Гарант. URL: https://base.garant.ru/70368570 (дата обращения: 18.01.2020).

12. Shangareev R.R. The Formula for Determining Motivation Indicators in the Occupational Risk Management System // IOP Conference Series Science and Engineering. 2019. Vol. 560. P. 012201. DOI: 10.1088/1757899X/560/1/012201.

13. Шангареев Р.Р. Мотивация работников - основной механизм системы управления профессиональными рисками на производстве // Сетевое издание «Нефтегазовое дело». 2018. № 3. С. 180-198. DOI: 10.17122/ogbus-2018-3-180-198. 
14. Ворошилов С.П., Новиков Н.Н., Файнбург Г.З. Основы методики оценки уровня профессионального риска работника, обусловленного уровнем его профессиональной компетентности // HR-Portal. 11.04.2012. URL: http://www.hr-portal.ru/article/osnovy-metodiki-ocenki-urovnya-professi-onalnogoriska-rabotnika-obuslovlennogo-urovnem-ego (дата обращения: 17.01.2020).

\section{References}

1. Abdrakhimov Yu.R., Shangareev R.R. Ob aktual'nosti voprosov izucheniya professional'nykh riskov $\mathrm{v}$ Rossii [On the Relevance of Studying Professional Risks in Russia]. Sbornik trudov mezhdunarodnoi nauchnotekhnicheskoi konferentsii «Sovremennye tekhnologii v neftegazovom dele 2014»: V 2 T. [Proceedings of the International Scientific and Technical Conference «Modern Technologies in the Oil and Gas Business - 2014»: in 2 Vol.]. Ufa, Arkaim Publ, 2014, Vol. 2, pp. 7-10. [in Russian].

2. Zubkova A., Sushkina A. Modernizatsiya sistemy upravleniya okhranoi truda [Modernization of OSH Management System]. Kadrovik - Personnel, 2012, No. 7, pp. 62-66. [in Russian].

3. Prikaz Rostekhnadzora № 339 ot 02.09.2019. Doklad o pravoprimenitel'noi praktike kontrol'no-nadzornoi deyatel'nosti v Federal'noi sluzhbe po ekologicheskomu, tekhnologicheskomu i atomnomu nadzoru pri osushchestvlenii federal'nogo gosudarstvennogo nadzora $v$ oblasti promyshlennoi bezopasnosti za 6 mesyatsev 2019 goda [Order of Rostechnadzor No. 339 of September 02, 2019. Report on the Enforcement Practice of Control and Supervision Activities in the Federal Service for Ecological, Technological and Nuclear Supervision in the Implementation of Federal State Supervision in the Field of Industrial Safety for 6 Months of 2019]. Konsortsium Kodeks. Available at: http://docs2.cntd.ru/document/561135145 (accessed 14.01.2020). [in Russian]. 
4. Crednyaya zarplata po regionam Rossii i v drugikh stranakh mira v 2019 godu [The Average Salary in the Regions of Russia and in Other Countries of the World in 2019]. Delovaya zhizn' - Business Life. Available at: http://bslife.ru/rabota/3/srednyaya-zarplata2019.html (accessed 16.01.2020). [in Russian].

5. Shangareev R.R. Role of Employee Motivation in an Industrial Occupational Risk Management System. IOP Conference Series Earth and Environmental Science, 2018, Vol. 194, No. 2, pp. 022033. DOI: 10.1088/17551315/194/2/022033.

6. Guseinova E.L. Kompetentnost' i kompetentsiya [Competence]. Sbornik trudov mezhdunarodnoi nauchno-tekhnicheskoi konferentsii, posvyashchennoi 60-letiyu filiala "Sovremennye tekhnologii v neftegazovom dele - 2016": V 2 T. [Proceedings of the International Scientific and Technical Conference Dedicated to the 60th Anniversary of the Branch «Modern Technologies in the Oil and Gas Business - 2016»: in 2 Vol.]. Ufa, UGNTU Publ., 2016, Vol. 2, pp. 224-227. [in Russian].

7. Shangareev R.R., Siraev A.Z. Identifikatsiya i otsenka professional'nykh riskov pri pogruzochno-razgruzochnykh rabotakh na ob"ektakh dobychi nefti i gaza [Identification and Assessment of Occupational Hazards in Loading and Unloading of Oil and Gas]. Materialy 46-i Vserossiiskoi nauchno-tekhnicheskoi konferentsii molodykh uchenykh, aspirantov $i$ studentov s mezhdunarodnym uchastiem: V 2 T. [Materials of the 46th All-Russian Scientific and Technical Conference of Young Scientists, Graduate Students and Students with International Participation: in 2 Vol.]. Ufa, UGNTU Publ., 2019, Vol. 2, pp. 199-203. [in Russian]. 
8. Obstoyatel'stva i prichiny krupnykh avarii i neschastnykh sluchaev, proisshedshikh na ob"ektakh neftegazodobychi v 1-m polugodii $2011 \mathrm{~g}$. [Circumstances and Causes of Major Accidents and Accidents that Occurred at Oil and Gas Production Facilities in the 1st Half of 2011]. Informatsionnyi byulleten' Federal'noi sluzhby po ekologicheskomu, tekhnologicheskomu $i$ atomnomu nadzoru - Newsletter of the Federal Service for Ecological, Technological and Nuclear Supervision, 2011, No. 5 (56), pp. 5-8. URL: https://ib.safety.ru/assets/pdf/Bull_56/Bull_56_5-8.pdf (accessed 17.01.2020). [in Russian].

9. Trudovoi kodeks Rossiiskoi Federatsii ot 30.12.2001 № 197-FZ (s posl. izm. $i$ dop. ot 16.12.2019 g.) [Labor Code of the Russian Federation No. 197-FZ of December 30, 2001 (with the Additions and Amendments of December 16, 2019)]. Ofitsial'nyi internet-portal pravovoi informatsii. Available at: http://pravo.gov.ru/proxy/ips/?docbody=\&nd=102074279 (accessed 21.01.2020). [in Russian].

10. Federal'nyi zakon ot 21.07.1997 № 116-FZ «O promyshlennoi bezopasnosti opasnykh proizvodstvennykh ob"ektov» (s posl. izm. i dop. ot 29.07.2018) [RF Federal Law of July 21, 1997 No. 116- FZ «On Industrial Safety of Production Facilities» (with the Additions and Amendments of July 29, 2018)]. Moscow, Normatika Publ., 2019. 28 p. [in Russian].

11. Prikaz Rostekhnadzora № 101 ot 12.03.2013. Ob utverzhdenii Federal'nykh norm $i$ pravil $v$ oblasti promyshlennoi bezopasnosti «Pravila bezopasnosti $v$ neftyanoi $i$ gazovoi promyshlennosti» (s posl. izm. i dop. ot 12.01.2015) [Order of Rostechnadzor No. 101 of March 12, 2013. On the Approval of the Federal Norms and Rules in the Field of Industrial Safety «Safety Rules in the Oil and Gas Industry» (with the Additions and Amendments of January 12, 2015)]. Informatsionno-pravovoe obespechenie Garant. Available at: https://base.garant.ru/70368570 (accessed 18.01.2020). [in Russian]. 
12. Shangareev R.R. The Formula for Determining Motivation Indicators in the Occupational Risk Management System. IOP Conference Series Science and Engineering, 2019, Vol. 560, pp. 012201. DOI: 10.1088/1757899X/560/1/012201.

13. Shangareev R.R. Motivatsiya rabotnikov - osnovnoi mekhanizm sistemy upravleniya professional'nymi riskami na proizvodstve [Employees Motivation - the Basic Mechanism of Professional Risks on Production Management Systems]. Setevoe izdanie «Neftegazovoe delo» - Online Edition «Oil and Gas Business», 2018, No. 3, pp. 180-198. DOI: 10.17122/ogbus-2018-3-180-198. [in Russian].

14. Voroshilov S.P., Novikov N.N., Fainburg G.Z. Osnovy metodiki otsenki urovnya professional'nogo riska rabotnika, obuslovlennogo urovnem ego professional'noi kompetentnosti [The Basis of the Methodology for Assessing the Level of Professional Risk of an Employee, due to the Level of His Professional Competence]. HR-Portal. 11.04.2012. Available at: http://www.hrportal.ru/article/osnovy-metodiki-ocenki-urovnya-professionalnogo-riska-rabotnika-obuslovlennogo-urovnem-ego (accessed 17.01.2020). [in Russian]

\section{Сведения об авторе}

\section{About the author}

Шангареев Рустам Раисович, канд. техн. наук, доцент кафедры «Механика и технология машиностроения», УГНТУ, филиал, г. Октябрьский, Российская Федерация

Rustam R. Shangareyev, Candidate of Engineering Sciences, Assistant Professor of Mechanics and Machine Building Technology Department, USPTU, Branch, Oktyabrskiy, Russian Federation

e-mail: shagu64@mail.ru 